\title{
Patient factors associated with difficult flexible bronchoscopic intubation under general anesthesia: a prospective observational study
}

\section{Facteurs liés au patient associés à une intubation difficile avec bronchoscope flexible sous anesthésie générale: une étude observationnelle prospective}

\author{
Taher Touré, MD - Stephan R. Williams, MD, PhD (iD - Mahmoud Kerouch, MD • \\ Monique Ruel, RN, CCRP
}

Received: 15 May 2019/Revised: 11 December 2019/Accepted: 13 December 2019/Published online: 17 January 2020

(C) Canadian Anesthesiologists' Society 2020

\begin{abstract}
Purpose Patient characteristics associated with difficult tracheal intubation using a flexible bronchoscope (FB) under general anesthesia have not been prospectively evaluated. This observational study aimed to identify demographic and morphologic factors associated with difficult $F B$ intubation.

Methods We recruited 420 adult elective surgery patients undergoing tracheal intubation during general anesthesia. Patients characteristics were recorded including age, sex, weight, height, body mass index, American Society of Anesthesiologists physical status, history of snoring, obstructive sleep apnea, Mallampati score, upper lip bite test score, neck circumference and skinfold thickness, maximal neck flexion and extension angles, absence of teeth, Cormack and Lehane grade, presence of blood or secretions during intubation, as well as the inter-incisor, thyromental, sternothyroid, and manubriomental distances. The time (duration) needed to complete intubation (primary endpoint) and the number of attempts needed were correlated with these patient characteristics in a multivariable analysis.

Results Intubation was successful on the first attempt in 409/420 patients (97\%). Seven patients (1.7\%) needed more than one attempt. Failure to intubate with the FB occurred in four patients (1\%). A correlation was found
\end{abstract}

T. Touré, MD · S. R. Williams, MD, PhD ( $₫)$.

M. Kerouch, MD · M. Ruel, RN, CCRP

Département d'anesthésiologie, Centre hospitalier de

l'Université de Montréal, Montréal, QC, Canada

e-mail: stephan.williams@umontreal.ca between intubation duration and visibility impaired by secretions or blood $(P<0.001)$, higher neck skinfold thickness $(P<0.001)$, and larger endotracheal tube diameter (relative to a constant $5.5 \mathrm{~mm} \mathrm{FB;} P<0.001$ ).

Conclusions The presence of secretions or blood that impair FB glottic visualization, a larger diameter endotracheal tube on the same size FB, as well as higher neck skinfold thickness may prolong the duration of $F B$ intubation under general anesthesia.

Trial registration www.clinicaltrials.gov (NCT02769819); registered 5 May, 2016.

\section{Résumé}

Objectif Les caractéristiques des patients associées à une intubation trachéale difficile avec un bronchoscope flexible sous anesthésie générale n'ont pas été évaluées de façon prospective. Cette étude observationnelle avait pour but d'identifier les facteurs démographiques et morphologiques associés aux intubations difficiles avec un bronchoscope flexible.

Méthodes Nous avons recruté 420 patients adultes devant subir une intubation trachéale au cours d'une anesthésie générale pour une chirurgie élective. Les caractéristiques suivantes des patients ont été consignées : âge, sexe, poids, taille, indice de masse corporelle, score de l'American Society of Anesthesiologists, antécédents de ronflements et de syndrome d'apnée-hypopnée du sommeil, score de Mallampati, score du test de morsure de la lèvre supérieure, circonférence $d u$ cou et épaisseur du pli cutané cervical, angles maximums de flexion et extension $d u$ cou, absence de dents, grade de la classification de Cormack et Lehane, présence de sang ou de sécrétions 
pendant l'intubation, ainsi que les distances inter-incisives, menton-cartilage thyrö̈de, sterno-thyrö̈dienne et mentonmanubrium. Le temps nécessaire pour compléter l'intubation (critère d'évaluation principal) et le nombre de tentatives nécessaires ont été corrélés aux caractéristiques des patients dans une analyse multifactorielle.

Résultats L'intubation a été réussie dès la première tentative chez 409 patients sur 420 (97\%). Pour 7 patients $(1,7 \%$, il a fallu plus d'une tentative. Un échec de l'intubation avec bronchoscope flexible est survenu chez 4 patients (1\%). Une corrélation a été trouvée entre la durée de l'intubation et une mauvaise visualisation due à des sécrétions ou du sang $(P<0,001)$, un pli cutané cervical plus épais $(P<0,001)$, et un plus grand diamètre du tube endotrachéal (par rapport à un fibroscope souple constant de 5,5 $\mathrm{mm} ; P<0,001$ ).

Conclusions La présence de sang ou de sécrétions gênant la visualisation de la glotte, un diamètre du tube endotrachéal augmenté par rapport à celui du fibroscope flexible ainsi qu'une plus grande épaisseur du pli cutané cervical peuvent prolonger le temps d'intubation avec endoscope flexible sous anesthésie générale.

Enregistrement de l'essai clinique $w w w$.clinicaltrials. gov (NCT02769819); enregistré le 5 mai 2016.

Tracheal intubation is often performed in patients undergoing general anesthesia. Direct laryngoscopy (DL) is a standard method to visualize the glottis and insert an endotracheal tube (ETT) in the trachea. Unfortunately, morphological or pathological characteristics of some patients can make visualization of the glottis difficult, if not impossible, with DL. Research has provided clinicians with established criteria that help predict difficult intubation with DL. ${ }^{1-3}$ More recently, videolaryngoscopy (VL) has been proposed as a standard for airway management, ${ }^{4}$ but this type of device, as with any other, has limitations and cannot guarantee successful intubation in all cases. ${ }^{5,6}$ When intubation using DL or VL is expected to be difficult, it is recommended ${ }^{7}$ to use alternative intubation devices; however, which alternative is best for each patient and airway problem is not always obvious. The identification of patient characteristics that can guide the clinician in the selection of the appropriate alternative intubation tool therefore remains an active research area. ${ }^{8,9}$

The flexible bronchoscope $(\mathrm{FB})^{10,11}$ is an appealing option for endotracheal intubation when DL or VL are anticipated to be difficult. The FB presents many potential advantages compared with DL or VL. Being thin and flexible, the FB may stimulate the airway less, be more comfortable in the awake patient, be less traumatic, and may permit glottic visualization in patients where DL or $\mathrm{VL}$ is difficult. ${ }^{12}$ It is widely used for awake intubation and has a high success rate in trained hands ${ }^{11}$; however, not all patients will provide the necessary cooperation for awake intubation. The FB can also be used to intubate patients under general anesthesia, with a similarly high success rate. ${ }^{13,14}$ Use of the FB may be limited by equipment availability, operator training, airway collapse under general anesthesia, or other patient morphology and pathologic features. Nevertheless, a lack of established criteria predicting technical difficulty when used in such a situation makes it difficult to determine in which patient populations FB intubation under general anesthesia may be advantageous or disadvantageous compared with other methods. Therefore, this prospective observational study was designed to determine the patient characteristics associated with FB intubation difficulty under general anesthesia as indicated by intubation duration (primary endpoint) and the need for multiple attempts (or failure of the technique).

\section{Methods}

This study was approved by the Institutional Review Board of the Centre hospitalier de l'Université de Montréal (April 2016) and written informed consent was obtained from all subjects participating in the trial. This report also adheres to the applicable STROBE statement. ${ }^{15}$ The trial was registered prior to patient enrolment at clinicaltrials.gov (NCT02769819; principal investigator, Stephan Williams; 5 May, 2016).

A convenience sample of patients were considered for recruitment as they arrived for their elective neurosurgical, otorhinolaryngologic, thoracic, gynecologic, orthopedic, plastic, or general surgery under general anesthesia at the Centre hospitalier de l'Université de Montréal between 11 October 2016 and 11 September 2017. If the attending anesthesiologist planned for awake intubation, rapid sequence intubation, or anesthesia without neuromuscular blockade, the patient was not approached for recruitment. If the patient agreed to participate in the study, their characteristics were recorded before induction of anesthesia. These characteristics included age, sex, weight, height, American Society of Anesthesiologists physical status classification, history of snoring, diagnosis of obstructive sleep apnea, Mallampati score, upper lip bite test score, inter-incisor, thyromental, sternothyroid and manubriomental distances (in both flexion and extension), neck circumference, neck skinfold thickness (as assessed with a Slimguide; Creative Health Products, Plymouth, MI, 
USA), maximal neck flexion and extension angles, and the presence or absence of a dental prosthesis (partial or total).

The induction of anesthesia was left at the discretion of the attending anesthesiologist but had to include adequate preoxygenation with $100 \%$ oxygen $\left(\mathrm{O}_{2}\right)$ and complete neuromuscular blockade prior to intubation. The attending anesthesiologists had complete discretion to manage the airway as they saw fit if there was a concern at any time during the study protocol with regards to patient safety; any deviation to the standard protocol was noted. Two senior anesthesiology residents (M.K. and T.T.) performed every intubation. As suggested in the literature, each resident had performed a minimum of $40 \mathrm{FB}$ oral intubations under general anesthesia before beginning the study. ${ }^{16,17}$

After induction of anesthesia, the absence of motor response to a train of four simulation of the ulnar nerve confirmed adequate muscle relaxation. The patient's head was then positioned in a sniffing ${ }^{18}$ position and DL was performed using a size 4 MacIntosh laryngoscope. The best Cormack and Lehane (CL) grade visualized, with or without backwards upwards rightward pressure, ${ }^{19}$ was noted. The investigators then placed the patient's head back into a neutral position and any oropharyngeal secretions were systematically suctioned. A Williams Airway Intubator oropharyngeal airway $(9 \mathrm{~cm}$ for women or $10 \mathrm{~cm}$ for men, Mercury Medical, Clearwater, FL, USA) was then inserted to help direct the FB. ${ }^{20,21}$ An assistant then performed a jaw thrust while keeping the oropharyngeal airway centred (without applying downward pressure to push it towards the posterior pharynx). A $5.5 \mathrm{~mm}$ FB (CMAC FIVE, Storz, Mississauga, ON, Canada) was lubricated (Silkospray; Willy Rüsch Gmbh, Kernen-Rommelshausen, Germany), treated with an anti-fogging agent (Fred 2; Covidien, Mansfield, MA, USA), and mounted with an ETT (Shiley Hi-Lo Oral/Nasal Tube Cuffed; Covidien, MA, USA; size 7.0 for women and 8.0 for men) the tip of which was also lubricated (Muko; Cardinal Health Canada, Mississauga, ON, Canada). The FB was always inserted through the oropharyngeal airway before attempting to pass it through the glottis and into the trachea.

After the ETT was inserted into the trachea through the oropharyngeal airway, the ETT cuff was inflated and the FB withdrawn. The ventilation circuit was then connected, and ventilation was initiated. Repeated carbon dioxide waveforms on the capnograph confirmed tracheal placement of the ETT. The oropharyngeal airway was then removed.

The primary endpoint of intubation duration was defined as the time from insertion of the FB into the mouth until the appearance of the first capnographic waveform, which was measured by the attending anesthesiologist who was not blinded to group assignment. The number of attempts needed to successfully intubate the patient's trachea was also noted. An attempt was considered successful when endotracheal intubation was confirmed as described above. The attempt was noted as unsuccessful and the FB was withdrawn if intubation was not achieved $120 \mathrm{sec}$ after the insertion of the FB, a technical problem occurred, secretions or blood made visualization impossible, or any drop in oxygen saturation $\left(\mathrm{SaO}_{2}\right)$ considered clinically significant was noted by the attending anesthesiologist or the resident performing the intubation. The patient was then re-ventilated to restore the $\mathrm{SaO}_{2}$ if necessary before beginning another FB intubation attempt. At the operator's discretion, during subsequent FB intubation attempts, any secretions could once again be suctioned from the airway, and tongue extrusion or mobilization of its base using DL held by the assistant could be substituted for the oropharyngeal airway. After a maximum of three unsuccessful attempts at FB intubation, the airway was managed using another technique at the discretion of the attending anesthesiologist.

\section{Statistical analysis}

After consultation with the statistical service of the Centre de recherche du Centre hospitalier de l'Université de Montréal and based on a similarly designed study with the rigid bronchoscope previously done in our centre, ${ }^{22}$ linear regression was chosen to calculate the sample size needed. Assuming ten variables, an effect size of $0.05,90 \%$ power, and an alpha of $1 \%$ the sample size was estimated to be 420 patients. $^{23,24}$ A logarithmic transformation of the dependent variable was completed and univariate analyses were performed to evaluate the association between each patient characteristic and intubation duration. Spearman's coefficients were calculated (SPSS ${ }^{2}$ v. 24, IBM, Armonk, NY, USA), and variables significantly correlated with intubation duration in the univariate analysis were included in a subsequent multivariable analysis. We verified linearity by plotting all potential predictors against intubation duration. Standard transformations were performed on potential predictors and the correlation between intubation duration and the transformed predictors was assessed. Multivariable modeling was conducted using stepwise regression to identify those that remained significantly correlated with intubation duration, reducing the risk of confounding. Additional multivariable models were created, including all second-order interactions with blood/secretion impairing visibility, to test for a modification of effect between this variable and other predictors. Sensitivity analysis was conducted treating ordinal variables as categorical (instead of numerical). 
Mean intubation times for categorical variables significantly correlated with intubation duration in the multivariable analysis, and were subsequently compared using a $t$ test assuming unequal variances. Unless stated otherwise, data are presented as percentages or means (standard deviation [SD]). A $P<0.01$ was considered significant.

\section{Results}

Four hundred and thirty-seven patients were approached for the study. Seventeen patients refused to participate. All 420 patients enrolled completed the full protocol. No patient or data was excluded from the analysis. Intubation was successful on the first attempt in 409 (97.4\%) patients (Table 1); a second or third attempt was necessary in seven (1.7\%) patients; FB intubation was not successful in four (1\%) patients. The presence of abundant secretions despite systematic oral suctioning (including the only two cases of bloody secretions in the study) was noted in five of the seven patients who needed more than one attempt, and all four failed intubations.

Five patients required a second FB attempt, including three for abundant secretions, one because the oropharyngeal airway was not adequately held in the midline and had to be repositioned, and one patient who had a very unusual pharyngeal anatomy that precluded easy identification of the glottis. The two patients that required a third FB attempt had abundant secretions despite resuctioning and needed DL to clear a pathway to the glottis for the FB before being successfully intubated.

Of the four patients $(1 \%)$ who could not be intubated with the FB, two of these patients desaturated very rapidly despite preoxygenation with $100 \% \quad \mathrm{O}_{2}$, had abundant secretions on FB view, and had very difficult or impossible bag-mask ventilation when re-initiated. In those two patients, FB intubation was not reattempted; one was intubated successfully with a VL after an unsuccessful DL intubation attempt, while the other was intubated successfully with a VL. In one FB failure, presence of bloody secretions prevented visualization of the glottis with the FB, and intubation was performed using DL alone. Finally, in one failed FB intubation, the vision was impaired by secretions and FB fogging and as the patient had recovered from their succinylcholine muscle relaxation before FB intubation was achieved, the attending anesthesiologist decided against any further FB attempts and intubated this patient using DL.

The mean (SD) intubation duration with the FB by anesthesia trainees was 28 (22) sec. Univariate analysis found correlations between several patient characteristics and intubation duration (Table 2). Patient body mass index, neck circumference, neck skin fold thickness, short thyromental distance, limited neck flexion and extension range, higher CL grade, ETT size $(8.0$ vs $7.0 \mathrm{~mm}$, internal diameter in the context of a constant $5.5 \mathrm{~mm}$ FB outside diameter), and impaired visibility because of blood or secretions were all correlated with intubation duration. FB intubation in CL grade III patients necessitated one attempt for ten patients, two attempts for one patient, and was not successful in one patient. Excepting thyromental distance, for which we included a quadratic component in the multivariable model, all other variables included in the multivariable analysis showed a linear relationship. After multivariable analysis, three variables remained significantly correlated with intubation duration: impaired visibility, larger ETT size on the same $5.5 \mathrm{~mm} \mathrm{FB}$, and neck skinfold thickness (Table 2). Multivariable models testing for significant $2 \times 2$ interactions between impaired visibility and the other variables included in the multivariable model did not find significant interactions. Sensitivity analysis that treated ordinal variables as categorical provided the same conclusions (results not shown). Mean (SD) intubation times for categorical variables that significantly correlated with intubation duration are shown in Table 3.

\section{Discussion}

To be a viable alternative to $\mathrm{DL}$ or $\mathrm{VL}$, an alternative tracheal intubation method needs to be easy to learn, be quick to perform, have a high success rate, and have a low complication rate. In addition, identifiable criteria that predict difficulty with the technique need to be known so that the anesthesiologist can further increase success rates by selecting the most appropriate alternative for each clinical situation. The overall success rate of FB intubation under general anesthesia (GA) in the present study was $99 \%$, but intubation took longer in the presence of secretions or blood, larger neck skinfold thickness, and a larger ETT with the same size bronchoscope.

The mean (SD) intubation duration in this study with the FB by anesthesia trainees (with a previous experience of more than $40 \mathrm{FB}$ intubations) of 28 (22) sec is difficult to compare with other studies because of variations in the operator and the technique and the moment when the timer was started and stopped. This intubation duration is best seen as a surrogate of difficulty within the conditions defined by each study protocol. For example, if the time for insertion of the oropharyngeal airway was included, intubation duration in the present study would be five to ten seconds longer. Keeping this in mind, Cole et al. reported a mean (SD) FB intubation duration by trainees of 56 (24) sec defined from removal of the face mask to the 
Table 1 Patient characteristics

\begin{tabular}{|c|c|c|c|c|}
\hline \multirow[t]{2}{*}{ Patient characteristics } & \multicolumn{3}{|c|}{ Number of FB intubation attempts } & \multirow[t]{2}{*}{ Range } \\
\hline & 1 attempt $(n=409)$ & $2-3$ attempts $(n=7)$ & Failure $(n=4)$ & \\
\hline Age $(y r)$ & $54(15)$ & $55(12)$ & $69(28)$ & $18-92$ \\
\hline Male/female & $170(42 \%) / 239(58 \%)$ & $3(43 \%) / 4(57 \%)$ & $1(25 \%) / 3(75 \%)$ & \\
\hline Weight (kg) & $78(18)$ & $82(9)$ & $75(14)$ & $39-149$ \\
\hline Height (cm) & $166(9)$ & $165(8)$ & $169(9)$ & 144-194 \\
\hline BMI $\left(\mathrm{kg} \cdot \mathrm{m}^{-2}\right)$ & $28(6)$ & $30(5)$ & $27(6)$ & $16-53$ \\
\hline ASA physical status I/II/III & $93 / 241 / 75$ & $1 / 6 / 0$ & $0 / 3 / 1$ & $1-3$ \\
\hline History of snoring & $185(45 \%)$ & $3(43 \%)$ & $2(50 \%)$ & \\
\hline \multicolumn{5}{|l|}{ Sleep apnea } \\
\hline Suspected & $28(7 \%)$ & 0 & 0 & \\
\hline Confirmed & $7(2 \%)$ & 0 & 0 & \\
\hline Treated (CPAP) & $19(5 \%)$ & 0 & 0 & \\
\hline \multicolumn{5}{|l|}{ Mallampati class } \\
\hline 1 & $176(43 \%)$ & 0 & $2(50 \%)$ & \\
\hline 2 & $180(44 \%)$ & $4(57 \%)$ & 0 & \\
\hline 3 & $48(12 \%)$ & $2(29 \%)$ & $2(50 \%)$ & \\
\hline 4 & $5(1 \%)$ & $1(14 \%)$ & 0 & \\
\hline \multicolumn{5}{|l|}{ Upper lip bite test score } \\
\hline 1 & $239(58 \%)$ & $3(43 \%)$ & $3(75 \%)$ & \\
\hline 2 & $141(34 \%)$ & $3(43 \%)$ & $1(25 \%)$ & \\
\hline 3 & $29(7 \%)$ & $1(14 \%)$ & 0 & \\
\hline Inter-incisor distance (mm) & $45(8)$ & $40(13)$ & $48(14)$ & $20-75$ \\
\hline Thyromental distance $(\mathrm{mm})$ & $77(14)$ & $70(20)$ & $83(12)$ & $33-120$ \\
\hline Sternothyroid distance (mm) & $87(20)$ & $77(20)$ & $81(38)$ & $40-158$ \\
\hline Manubriomental distance in flexion (mm) & $38(19)$ & $42(15)$ & $32(14)$ & $0-100$ \\
\hline Manubriomental distance in extension (mm) & $162(24)$ & $146(15)$ & $166(41)$ & $90-240$ \\
\hline Neck circumference (mm) & $383(49)$ & $416(60)$ & $401(83)$ & $270-560$ \\
\hline Neck skinfold thickness (mm) & $4(3)$ & $3(2)$ & $4(2)$ & $1-19$ \\
\hline Total range of neck motion $\left({ }^{\circ}\right)$ & $111(18)$ & $112(16)$ & $115(27)$ & $25-170$ \\
\hline \multicolumn{5}{|l|}{ Cormack and Lehane grade* } \\
\hline 1 & $281(69 \%)$ & $4(57 \%)$ & $2(50 \%)$ & \\
\hline 2 & $118(29 \%)$ & $2(29 \%)$ & $1(25 \%)$ & \\
\hline 3 & $10(2 \%)$ & $1(14 \%)$ & $1(25 \%)$ & \\
\hline 4 & 0 & 0 & 0 & \\
\hline Visibility impaired by secretions:blood & 46:0 (11\%) & $5: 0(71 \%)$ & $4: 2(100 \%)$ & \\
\hline
\end{tabular}

Mean (standard deviation) or $n(\%)$ where indicated.

ASA = American Society of Anesthesiologists; BMI = body mass index; $\mathrm{CPAP}=$ continuous positive away pressure; $\mathrm{FB}=$ flexible bronchoscope.

*Backward upward rightward pressure (BURP) was systematically performed if the vocal cords were not visualized with direct laryngoscopy. The best available Cormack and Lehane grade was noted.

detection of exhaled carbon dioxide. ${ }^{13}$ There was no mention of suctioning or the use of an oropharyngeal airway in that study. Tawfeek et al. reported mean (SD) nasal FB intubation duration using smaller ETTs of 19 (27) sec, defined from FB insertion to first detection of exhaled carbon dioxide. ${ }^{14}$ Using a protocol similar to the current study except for the absence of systematic insertion of an oropharyngeal airway, Tremblay et al. used a GlideScope ${ }^{8}{ }^{8}$ (Verathon, Bothell, WA, USA) and reported a mean $(\mathrm{SD})$ intubation duration of 21 (14) sec, while Nowakowski et al. used a Bonfils ${ }^{\circledR}$ (Storz, Mississauga, ON, Canada) rigid bronchoscope, and 
Table 2 Significant correlations between intubation duration and patient characteristics

\begin{tabular}{llll}
\hline Patient characteristics & $\begin{array}{l}\text { Correlation coefficient } \\
(95 \% \text { CI })\end{array}$ & Univariate $P$ & Multivariable $P$ \\
\hline Impaired visibility (blood, secretions) & $0.30(0.21$ to 0.39$)$ & $<0.001$ & $<0.001$ \\
Skin fold thickness & $0.27(0.18$ to 0.36$)$ & $<0.001$ & $<0.001$ \\
ETT ID $8.0 v s 7.0 *$ & $0.18(0.01$ to 0.28$)$ & $<0.001$ & $<0.001$ \\
Cormark Lehane (with BURP as necessary) & $0.22(0.13$ to 0.30$)$ & $<0.001$ & - \\
BMI & $0.21(0.11$ to 0.30$)$ & $<0.001$ & - \\
Neck circumference & $0.21(0.13$ to 0.30$)$ & 0.002 & - \\
Neck flexion-extension & $-0.15(-0.24$ to -0.06$)$ & 0.005 & - \\
Thyromental distance & $-0.14(-0.23$ to -0.04$)$ & & \\
\hline
\end{tabular}

*A 5.5-mm outer diameter flexible bronchoscope was used throughout the study.

Spearman's coefficients were calculated using SPSS ${ }^{\circledR}$ v. 24, including $95 \%$ confidence intervals using the integrated Bootstrap function. Multivariable analysis was performed with variables that showed a correlation on univariate analysis, using a stepwise regression to identify those that remained significantly correlated with intubation duration.

$\mathrm{BMI}=$ body mass index; $\mathrm{BURP}=$ backwards upwards rightwards pressure $\mathrm{CI}$ = confidence interval; $\mathrm{ETT}$ ID = endotracheal tube inner diameter; $\mathrm{FB}=$ flexible bronchoscope.

Table 3 Intubation times for categorical variables significantly correlated with intubation duration

\begin{tabular}{|c|c|c|c|c|}
\hline \multicolumn{2}{|l|}{ Categorical variable } & \multirow{2}{*}{$\begin{array}{l}\text { Time, sec } \\
25(16)\end{array}$} & \multirow{2}{*}{$\begin{array}{l}\text { Difference } \\
24.6 \mathrm{sec}\end{array}$} & \multirow{2}{*}{$\begin{array}{l}P \\
0.001\end{array}$} \\
\hline Visibility & Good & & & \\
\hline & Impaired by secretions/blood & 49 (39) & (99\% CI, 11.4 to 42.3 ) & \\
\hline ETT size & $7.0 \mathrm{~mm}$ ID & $25(18)$ & $6.5 \mathrm{sec}$ & 0.007 \\
\hline (5.5 mm bronchoscope) & $8.0 \mathrm{~mm}$ ID & $31(26)$ & (99\% CI, 0.8 to 12.7 ) & \\
\hline
\end{tabular}

$\mathrm{CI}=$ confidence interval; ETT $=$ endotracheal tube; $\mathrm{ID}=$ inner diameter; $\mathrm{SD}=$ standard deviation.

reported a mean intubation duration of 26 (13) sec. $^{22}$ Overall, even when differences in the definition of intubation duration are taken into account, these findings suggest that differences in overall success rates or intubation duration may not be a major factor when deciding between these alternative techniques.

The overall success rate of FB intubation under GA in the present study was $99 \%$ (with $97.4 \%$ success on the first attempt). This is comparable to the $96 \%$ to $100 \%$ success rates found in other studies where a FB was used to intubate patients under $\mathrm{GA}^{13,14}$ or for awake intubation. $^{25,26}$ It is also comparable to the success rates found in similar studies that examined other alternatives to DL, such as the GlideScope ${ }^{\circledR}$ or Bonfils ${ }^{\circledR}$ rigid bronchoscope $\left(99,8 \%\right.$ and $99 \%$ respectively). ${ }^{8,22}$ The small number of patients not successfully intubated on the first attempt in the present study precluded the possibility of quantitative analysis of the correlation between the number of attempts needed or intubation failure and patient characteristics. A description of each patient in which multiple attempts were necessary is provided (see Results). Repeated aspiration or tongue traction did not make intubation possible in two patients; these patients were then intubated using DL to open a viewing channel for FB insertion. Tongue traction may not be superior to the use of an oropharyngeal airway to clear the oropharynx of a relaxed tongue. Nevertheless, using DL or VL as an aid to clear the base of the tongue from the posterior pharyngeal wall may increase the chance of success in certain cases, as suggested by other research. $^{27-29}$

Multivariable analysis quantified the correlation between several patient characteristics and intubation duration. The presence of secretions (bloody or not) impairing FB visibility was a reliable predictor of longer intubation duration. Impaired visibility was noted in nine of 11 unsuccessful first attempt intubations. These findings strongly support the notion that FB intubation may not be a first choice or a successful rescue device in patients that present pre-induction with excessive airway secretions or bloody airway trauma, and that secretions should always be thoroughly suctioned before FB insertion. Although 
evidence of efficacy is not available, several strategies not used in the present study have been advocated to address the problem of secretions during FB intubation. Some authors suggest systematic administration of an antisialagogue $^{11,30}$ when FB intubation is planned, but glycopyrrolate would not have time to function in a rescue scenario, and has several relative contraindications (https://www.pdr.net/drug-summary/Robinul-Injectionglycopyrrolate-1135) that would have limited the generalizability of the results of the present study. Others have used a continuous flow of oxygen through the working channel of the FB not only as a means of oxygenation but also to clear secretions off the tip of the FB as it is advanced in the patient airway. ${ }^{30}$ But at high flow rates, complications including possible barotrauma are also associated with this technique. ${ }^{31}$

Neck skinfold thickness was also correlated with intubation duration. Obesity is a well-known predictor of difficult mask ventilation, ${ }^{32-34}$ but study results are conflicting about its role as a predictor of difficult intubation with DL or VL. ${ }^{35-39}$ The correlation found in this study might suggest a more significant role of adipose tissue distributed preferentially in the neck region, although more data will be needed to confirm this suggestion. Nevertheless, the presence of obesity and particularly adipose tissue in the neck may warrant caution before choosing to intubate with the FB either as a first choice or as a rescue device under GA.

When the same $5.5 \mathrm{~mm}$ diameter FB was used for both ETT sizes, the use of an $8.0 \mathrm{~mm}$ internal diameter ETT was associated with longer intubation duration compared with a $7.0 \mathrm{~mm}$ tube. Nevertheless, the larger tube was not overrepresented in cases where FB intubation failed. Knowing that we systematically used smaller sized ETTs for women, differences in FB intubation duration could be associated with patient sex. ${ }^{40}$ Nevertheless, difficulty in advancing the ETT on a properly placed FB in the trachea (i.e., impingement or "hang-up") is a known cause of difficult or failed FB intubation, and a larger diameter ETT relative to the FB diameter is associated with a higher probability of impingement, as previously shown by Koga et al. ${ }^{41}$ Asai et al. reported an incidence of 0 to $90 \%$ for difficulty passing an ETT in the trachea over an orally inserted $\mathrm{FB}^{42}$ Impingement over laryngeal structures (mainly the right arytenoid cartilage) ${ }^{43}$ or deviation of the ETT towards the esophagus creating resistance to the advancement of the ETT $^{44}$ have been described. Many solutions have been suggested to surmount this difficulty, from selecting a smaller ETT to specific ETT types involving more flexible narrow-wall designs and/or different tip designs with different bevel shapes and orientations. ${ }^{45}$ More flexible ETTs were not used in the present study as extensive institutional experience shows that they are more prone to kinking during some of the long cases included in this series. One simple maneuver is to rotate the tube $90^{\circ}$ anticlockwise (i.e., bevel oriented posteriorly $)^{42,46}$ to remove the tip from the right arytenoid. This technique was used successfully in this study regardless of tube size when impingement occurred.

This study does have some limitations. First, as with every airway device, operators with more or less experience than the anesthesia residents who performed the FB intubations in this study may obtain different results. Also, the operators who performed the FB intubation also gathered all other morphometric and morphologic data. Their performance during FB intubation could theoretically have been influenced by the information previously gathered. Though every effort was made to keep exclusion criteria to a minimum to maximize generalizability, results may not be applicable to patients undergoing tracheal intubation without neuromuscular blockade. Also, for safety reasons, patients were excluded if the attending anesthesiologist planned awake intubation. This undoubtedly excluded several patients with a high risk of, or known, difficult DL or VL intubation. Despite every effort for an atraumatic technique, two patients presented with bloody secretions in the airway during FB; it cannot be ascertained whether previous DL, aspiration of secretions, insertion of the intubating airway, or the FB itself were the cause of the bleeding. Finally, FB requires specialized equipment and personnel as well as additional resources that may not be available in every clinical setting.

Despite awake FB intubation being a mainstay of several difficult airway management algorithms, several studies have shown that anesthesiologists refrain from performing awake FB intubation, even when indicated. The reasons for this include fear of failure and fear of causing distress to a conscious patient. ${ }^{47,48}$ Though FB intubation under GA cannot be substituted for awake FB intubation, the high success rates for FB intubation under GA shown in the present study could provide clinicians with a useful alternative for acquiring and maintaining FB intubation skills in patients for whom awake intubation is not indicated. This could then reduce their concerns about awake FB intubation failing or causing the patient discomfort. Studies have also shown that putting patients under general anesthesia is an appropriate way to teach FB intubation to trainees. ${ }^{13}$ The present results support and quantify the safety and efficacy of FB intubation under GA, without proposing it as a substitute for patients in whom awake FB intubation is indicated.

In conclusion, longer duration of FB intubation under GA is related to the presence of secretions or blood, greater neck skinfold thickness, and the use of a larger ETT relative to FB diameter. Though FB intubation success 
rates were high in the present study, anesthesiologists should take care to limit the presence of secretions and select the smallest ETT size relative to the FB diameter. In case of limited visualization on first attempt, the use of DL or VL to open a channel for the FB in the oropharynx may increase the probability of success.

Author contributions Taher Touré and Stephan R. Williams helped design the study, conduct the study, analyze the data, and write the manuscript. Mahmoud Kerouch helped design the study and conduct the study. Monique Ruel helped design the study, conduct the study, analyze the data, and write the manuscript. Taher Touré, Stephan R. Williams, and Mahmoud Kerouch have seen the original study data, reviewed the analysis of the data, and approved the final manuscript. Monique Ruel has seen the original study data, approved the final manuscript, and was responsible for archiving the study files.

\section{Conflicts of interest None.}

Funding source Internal funding. Equipment loan provided by Karl Storz Endoscopy Canada Ltd.

Editorial responsibility This submission was handled by Dr. Hilary P. Grocott, Editor-in-Chief, Canadian Journal of Anesthesia.

Data availability Protocol available at: https://clinicaltrials.gov/ ct2/show/NCT02769819.

\section{References}

1. Heinrich S, Birkholz T, Irouschek A, Ackermann A, Schmidt J. Incidences and predictors of difficult laryngoscopy in adult patients undergoing general anesthesia : a single-center analysis of 102,305 cases. J Anesth 2013; 27: 815-21.

2. Khan ZH, Mohammadi M, Rasouli MR, Farrokhnia F, Khan RH. The diagnostic value of the upper lip bite test combined with sternomental distance, thyromental distance, and interincisor distance for prediction of easy laryngoscopy and intubation: a prospective study. Anesth Analg 2009; 109: 822-4.

3. Karkouti K, Rose DK, Wigglesworth D, Cohen MM. Predicting difficult intubation: a multivariable analysis. Can J Anesth 2000; 47: 730-9.

4. Zaouter C, Calderon J, Hemmerling TM. Videolaryngoscopy as a new standard of care. Br J Anaesth 2015; 114: 181-3.

5. Aziz MF, Healy D, Kheterpal S, Fu RF, Dillman D, Brambrink $A M$. Routine clinical practice effectiveness of the Glidescope in difficult airway management: an analysis of 2,004 Glidescope intubations, complications, and failures from two institutions. Anesthesiology 2011; 114: 34-41.

6. Lewis SR, Butler AR, Parker J, Cook TM, Schofield-Robinson OJ, Smith AF. Videolaryngoscopy versus direct laryngoscopy for adult patients requiring tracheal intubation: a Cochrane systematic review. Br J Anaesth 2017; 119: 369-83.

7. Apfelbaum JL, Hagberg CA, Caplan RA, et al. Practice Guidelines for Management of the Difficult Airway: an updated report by the American Society of Anesthesiologists Task Force on Management of the Difficult Airway. Anesthesiology 2013; 118: 251-70.

8. Tremblay $M H$, Williams $S$, Robitaille A, Drolet $P$. Poor visualization during direct laryngoscopy and high upper lip bite test score are predictors of difficult intubation with the
GlideScope videolaryngoscope. Anesth Analg 2008; 106: 1495500.

9. Kleine-Brueggeney $M$, Greif $R$, Schoettker P, Savoldelli GL, Nabecker $S$, Theiler $L G$. Evaluation of six videolaryngoscopes in 720 patients with a simulated difficult airway: a multicentre randomized controlled trial. Br J Anaesth 2016; 116: 670-9.

10. Calder I. Murphy P. A fibre-optic endoscope used for nasal intubation. Anaesthesia 1967; 22: 489-91. Anaesthesia 2010; 65: 1133-6.

11. Collins SR, Blank RS. Fiberoptic intubation: an overview and update. Respir Care 2014; 59: 865-78.

12. Vaidya PJ, Leuppi JD, Chhajed PN. The evolution of flexible bronchoscopy: from historical luxury to utter necessity!! Lung India 2015; 32: 208-10.

13. Cole AF, Mallon JS, Rolbin SH, Ananthanarayan C. Fiberoptic intubation using anesthetized, paralyzed, apneic patients. Results of a resident training program. Anesthesiology 1996; 84: 1101-6.

14. Tawfeek MM, Abdelbaky AM. Is fiberoptic bronchoscope a good intubating choice in anesthetized patients with anticipated difficult intubation? Egypt J Anaesth 2011; 27: 157-61.

15. von Elm E, Altman DG, Egger $M$, et al. Strengthening the reporting of observational studies in epidemiology (STROBE) statement: guidelines for reporting observational studies. BMJ 2007; 335: 806-8.

16. Johnson C, Roberts JT. Clinical competence in the performance of fiberoptic laryngoscopy and endotracheal intubation: a study of resident instruction. J Clin Anesth 1989; 1: 344-9.

17. Smith JE, Jackson AP, Hurdley J, Clifton PJ. Learning curves for fibreoptic nasotracheal intubation when using the endoscopic video camera. Anaesthesia 1997; 52: 101-6.

18. Prakash S, Rapsang AG, Mahajan S, Bhattacharjee S, Singh R, Gogia AR. Comparative evaluation of the sniffing position with simple head extension for laryngoscopic view and intubation difficulty in adults undergoing elective surgery. Anesthesiol Res Pract 2011. DOI: https://doi.org/10.1155/2011/297913.

19. Lam AM. The difficult airway and BURP — a truly Canadian perspective. Can J Anesth 1999; 46: 298-9.

20. Greenland $K B$, Irwin $M G$. The Williams Airway Intubator, the Ovassapian Airway and the Berman Airway as upper airway conduits for fibreoptic bronchoscopy in patients with difficult airways. Curr Opin Anaesthesiol 2004; 17: 505-10.

21. Dillane D. The Williams Airway Intubator. Can J Anesth 2018; 65: 722-3.

22. Nowakowski M, Williams S, Gallant J, Ruel M, Robitaille A. Predictors of difficult intubation with the Bonfils rigid fiberscope. Anesth Analg 2016; 122: 1901-6.

23. Cohen J, Cohen P, West SG, Aiken LS. Applied Multiple Regression/Correlation Analysis for the Behavioral Sciences. 3rd ed. Mahwah, NJ, US: Lawrence Erlbaum Associates Publishers; 2003.

24. Soper DS; Free Statistics Calculators. A-Priori Sample Size Calculator for Multiple Regression [Software]- 2018. Available from URL: http://Www.Danielsoper.Com/Statcalc (accessed December 2019).

25. Ovassapian A, Yelich SJ, Dykes MH, Brunner EE. Fiberoptic nasotracheal intubation-incidence and causes of failure. Anesth Analg 1983; 62: 692-5.

26. Law JA, Morris IR, Brousseau PA, de la Ronde S, Milne AD. The incidence, success rate, and complications of awake tracheal intubation in 1,554 patients over 12 years: an historical cohort study. Can J Anesth 2015; 62: 736-44.

27. Stacey MR, Rassam S, Sivasankar R, Hall JE, Latto IP. A comparison of direct laryngoscopy and jaw thrust to aid fibreoptic intubation. Anaesthesia 2005; 60: 445-8.

28. Johnson C, Hunter J, Ho E, Bruff C. Fiberoptic intubation facilitated by a rigid laryngoscope. Anesth Analg 1991; 72: 714. 
29. ClinicalTrials.gov. Macintosh Laryngoscope Assisted Fiberoptic Intubation. Available from URL: https://clinicaltrials.gov/ct2/ show/NCT03310866. First posted October 16, 2017. (accessed December 2019).

30. Ramkumar $V$. Preparation of the patient and the airway for awake intubation. Indian J Anaesth 2011; 55: 442-7.

31. Hemmerling TM, Bracco D. Subcutaneous cervical and facial emphysema with the use of the Bonfils fiberscope and high-flow oxygen insufflation. Anesth Analg 2008; 106: 260-2.

32. Langeron $O$, Masso E, Huraux $C$, et al. Prediction of difficult mask ventilation. Anesthesiology 2000; 92: 1229-36.

33. Cattano D, Killoran PV, Cai C, Katsiampoura AD, Corso RM, Hagberg $C A$. Difficult mask ventilation in general surgical population: observation of risk factors and predictors. F1000Research 2014. DOI: https://doi.org/10.12688/ f1000research.5131.1.

34. Riad W, Vaez MN, Raveendran R, et al. Neck circumference as a predictor of difficult intubation and difficult mask ventilation in morbidly obese patients: a prospective observational study. Eur J Anaesthesiol 2016; 33: 244-9.

35. Uribe AA, Zvara DA, Puente EG, Otey AJ, Zhang J, Bergese SD. BMI as a predictor for potential difficult tracheal intubation in males. Front Med 2015. DOI: https://doi.org/10.3389/fmed.2015. 00038.

36. Dixit A, Kulshrestha M, Mathews JJ, Bhandari M. Are the obese difficult to intubate? Br J Anaesth 2014; 112: 770-1.

37. Lundstrøm LH, Mфller AM, Rosenstock C, Astrup G, Wetterslev J. High body mass index is a weak predictor for difficult and failed tracheal intubation: a cohort study of 91,332 consecutive patients scheduled for direct laryngoscopy registered in the Danish Anesthesia Database. Anesthesiology 2009; 110: 266-74.

38. Saasouh W, Laffey K, Turan A, et al. Degree of obesity is not associated with more than one intubation attempt: a large centre experience. Br J Anaesth 2018; 120: 1110-6.

39. Hoshijima H, Denawa $Y$, Tominaga A, Nakamura C, Shiga T, Nagasaka $H$. Videolaryngoscope versus Macintosh laryngoscope for tracheal intubation in adults with obesity: a systematic review and meta-analysis. J Clin Anesth 2018; 44: 69-75.

40. Kalezic N, Milosavljevic R, Paunovic I, et al. The incidence of difficult intubation in 2000 patients undergoing thyroid surgery a single center expirience. Vojnosanit Pregl 2009; 66: 377-82.

41. Koga K, Asai T, Latto IP, Vaughan RS. Effect of the size of a tracheal tube and the efficacy of the use of the laryngeal mask for fibrescope-aided tracheal intubation. Anaesthesia 1997; 52: 1315 .

42. Asai $T$, Shingu $K$. Difficulty in advancing a tracheal tube over a fibreoptic bronchoscope: incidence, causes and solutions. Br J Anaesth 2004; 92: 870-81.

43. Katsnelson T, Frost EA, Farcon E, Goldiner PL. When the endotracheal tube will not pass over the flexible fiberoptic bronchoscope. Anesthesiology 1992; 76: 151-2.

44. Asai T, Murao K, Johmura S, Shingu K. Effect of cricoid pressure on the ease of fibrescope-aided tracheal intubation. Anaesthesia 2002; 57: 909-13.

45. Joo HS, Naik VN, Savoldelli GL. Parker Flex-Tip are not superior to polyvinylchloride tracheal tubes for awake fibreoptic intubations. Can J Anesth 2005; 52: 297-301.

46. Marfin AG, Iqbal R, Mihm F, Popat MT, Scott SH, Pandit JJ. Determination of the site of tracheal tube impingement during nasotracheal fibreoptic intubation. Anaesthesia 2006; 61: 646-50.

47. Fitzgerald E, Hodzovic I, Smith AF. 'From darkness into light': time to make awake intubation with videolaryngoscopy the primary technique for an anticipated difficult airway? Anaesthesia 2015; 70: 387-92.

48. Popat MT, Srivastava M, Russell R. Awake fibreoptic intubation skills in obstetric patients: a survey of anaesthetists in the Oxford region. Int J Obstet Anesth 2000; 9: 78-82.

Publisher's Note Springer Nature remains neutral with regard to jurisdictional claims in published maps and institutional affiliations. 